University of Nebraska - Lincoln

DigitalCommons@University of Nebraska - Lincoln

Faculty Papers and Publications in Animal

Science

Animal Science Department

January 1978

\title{
STUDIES ON THE FEASIBILITY OF PREDICTING FEEDLOT PERFORMANCE FROM CERTAIN LABORATORY GRAIN ANALYSES
}

M. L. Galyean

Oklahoma State University, Stillwater

D. G. Wagner

Oklahoma State University, Stillwater

R. K. Johnson

University of Nebraska-Lincoln, rjohnson5@unl.edu

Follow this and additional works at: https://digitalcommons.unl.edu/animalscifacpub

Part of the Animal Sciences Commons

Galyean, M. L.; Wagner, D. G.; and Johnson, R. K., "STUDIES ON THE FEASIBILITY OF PREDICTING FEEDLOT PERFORMANCE FROM CERTAIN LABORATORY GRAIN ANALYSES" (1978). Faculty Papers and Publications in Animal Science. 14.

https://digitalcommons.unl.edu/animalscifacpub/14

This Article is brought to you for free and open access by the Animal Science Department at DigitalCommons@University of Nebraska - Lincoln. It has been accepted for inclusion in Faculty Papers and Publications in Animal Science by an authorized administrator of DigitalCommons@University of Nebraska - Lincoln. 


\title{
STUDIES ON THE FEASIBILITY OF PREDICTING FEEDLOT PERFORMANCE FROM CERTAIN LABORATORY GRAIN ANALYSES ${ }^{1,2}$
}

\author{
M. L. Galyean ${ }^{3}$, D. G. Wagner and R. K. Johnson \\ Oklaboma State University ${ }^{4}$, Stillwater 74074
}

\section{SUMMARY}

Data from 14 cattle feeding trials were utilized to study the relationship between several laboratory analyses and animal feed intake (INTAKE), gain (ADG) and feed efficiency $(F / G)$. Laboratory analyses considered were 6,12 and $24 \mathrm{hr}$ in vitro dry matter disappearance (IV6, IV12, IV24, respectively); in vitro gas production in $1 \mathrm{hr}$ and $6 \mathrm{hr}$ (GP1 and GP6, respectively); and degree of gelatinization (GEL). A multiple regression equation with variables for treatment and trial classification, initial weight and the quadratic effect of initial weight was fit to the data. The effect of initial weight was significant for all three performance variables, and the quadratic effect was significant for ADG and F/G. A second model was fit excluding the treatment classification, and the maximum $R^{2}$ procedure was utilized to examine how well laboratory analyses accounted for variation among residuals from this second model. More variation was accounted for in the dependent variables $F / G$ (34.96\%) and INTAKE (17.81\%) than ADG (5.16\%) when a combination of all laboratory analyses except GEL was included in the model. Moreover, correlations between residuals of the second model and the laboratory analyses were higher for INTAKE and F/G than $A D G$ and were all negative for INTAKE and $F / G$, suggesting a negative response in intake and an improved $F / G$ ratio as starch alteration increases. Correlations between the laboratory analyses were generally quite high. This study suggests that no single laboratory analysis con-

\footnotetext{
${ }^{1}$ Journal Article 3282 of the Agricultural Experiment Station, Oklahoma State University, Stillwater 74074.

${ }^{2}$ The assistance of Drs. M. A. Brown and L. D. Young in statistical analyses is greatly appreciated.

${ }^{3}$ Department of Animal and Range Science, New Mexico State University.

${ }^{4}$ Animal Science Department.
}

sidered would be useful for the development of accurate, reliable equations for the prediction of feedlot performance, and combinations appear to have value only in the case of $F / G$ and INTAKE.

(Key Words: Multiple Regression, Feedlot Performance, Grain Analyses, Beef Cattle.)

\section{INTRODUCTION}

Numerous studies involving the feeding value of processed grains in high energy diets for finishing cattle have included laboratory evaluations of the grain. While it appears that laboratory evaluations such as in vitro gas production and degree of gelatinization yield valuable information with respect to the effect of processing on the starch fraction of the grain, little information exists on the relationship between laboratory analyses of grain and animal performance.

Albin et al. (1966) compared in vitro dry matter digestibility (IVDMD) of all concentrate diets with performance of feedlot steers receiving the same diets. Correlation coefficients of .88 and .99 were obtained between IVDMD and feedlot gain and efficiency, respectively. Klett and Ralson (1967) observed significant correlations between 12 and $24 \mathrm{hr}$ IVDMD and in vitro digestion of ether extract, dry matter, energy and crude fiber. Kumeno et al. (1967) evaluated diets containing concentrates in varying proportions up to $75 \%$ of the total diet by a $48 \mathrm{hr}$ IVDMD technique and simultaneous in vivo total tract evaluation in sheep. The correlation between IVDMD and in vivo DMD (.85) was highly significant. Trei et al. (1970) compared in vitro gas production by rumen microorganisms and IVDMD in processed grains. A correlation coefficient of .95 was found between gas production and IVDMD.

In this study, multiple regression and correlation analyses involving data from 14 feedlot trials were used in an effort to further investigate the relationship between animal perform- 
ance and laboratory analyses of processed grains. Correlations between the various laboratory analyses were also investigated.

\section{EXPERIMENTAL PROCEDURES}

Data from 14 cattle feeding trials involving the evaluation of processed grain were utilized to study the relationship between several laboratory analyses of grains and the feed intake (INTAKE), average daily gain (ADG) and feed efficiency $(F / G)$ of cattle receiving the same grains. INTAKE, ADG and F/G were all expressed as pen averages. The grains, processing methods and other variables involved in the 14 trials are shown in table 1. Laboratory analyses of the grains considered in this study were total in vitro dry matter disappearance after 6,12 and $24 \mathrm{hr}$ (IV6, IV12 and IV24, respectively) incubation periods; in vitro gas production after $1 \mathrm{hr}$ and $6 \mathrm{hr}$ (GP1 and GP6, respectively) and degree of gelatinization (GEL). Methods of laboratory analyses have been reported previously by Croka and Wagner (1975b). Laboratory data were collected over a number of years by different individuals using the same procedures at one location. References regarding the data for the 14 feeding trials are as follows: Aimone (1975), Aimone and Wagner (1977a,b), Croka and Wagner (1975a,b,c), Christiansen and Wagner (1974a,b), Martin (1973), and Schneider, (1971).

One hundred and sixty-two pens of cattle varying from three to five animals per pen were used in this study. Information on GEL was available for only 72 pens. One hundred and thirty pens had information pertaining to IV6, IV12, GP1 and GP6. All pens had data available for IV 24.

In an effort to remove as much variation as possible due to such factors as trial differences and pen differences in initial weight on test, measures of feedlot performance were first subjected to a regression analysis where the following model was fit:

$$
\mathrm{Y}=\beta \mathrm{o}+\alpha_{\mathrm{i}}+\mathrm{IW} \beta_{1}+\mathrm{IW}^{2} \beta_{2}+\epsilon
$$

Where: $\quad \mathrm{Y}=$ INTAKE $(\mathrm{kg})$, ADG $(\mathrm{kg})$ or $\mathrm{F} / \mathrm{G}$ $\beta o=y$ intercept

$\alpha_{i}=$ Treatment-trial classification variable, $\mathrm{i}=1,2, \ldots, 45$ (14 trials, 45 total treatments)

IW $=$ Initial weight on test in $\mathrm{kg} \cdot{ }^{75}=$ IW. 75

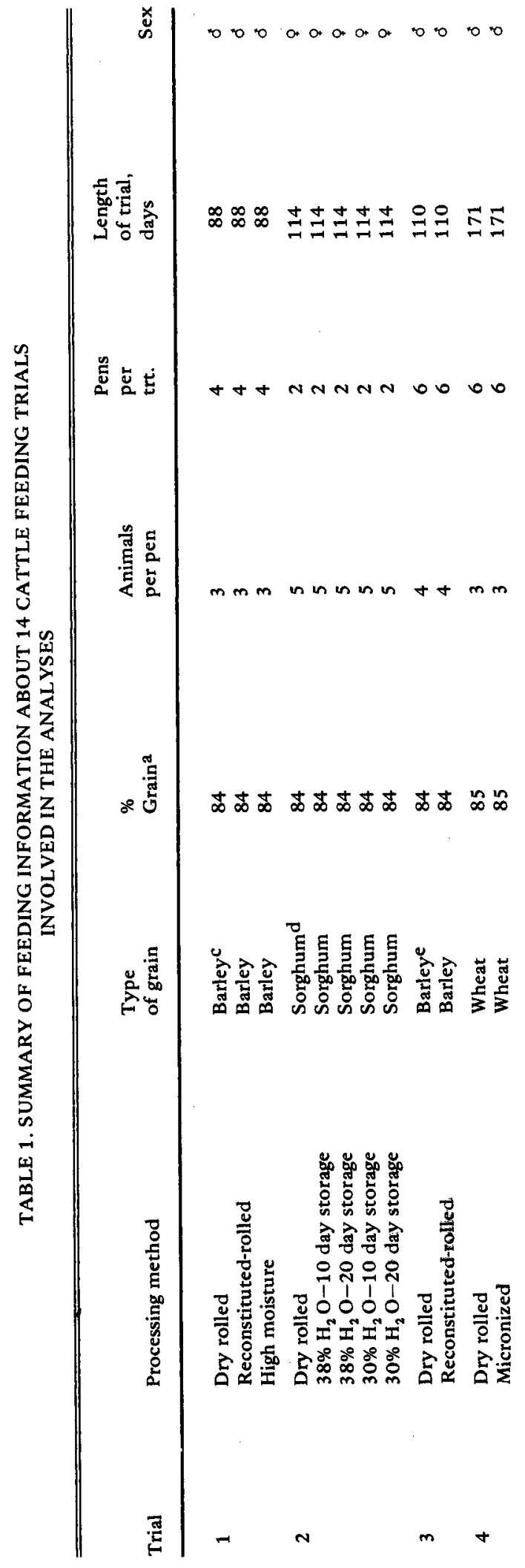




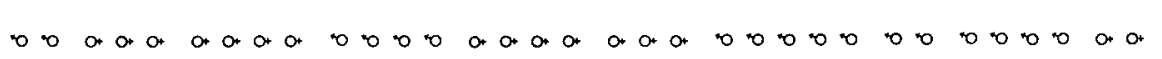

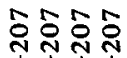

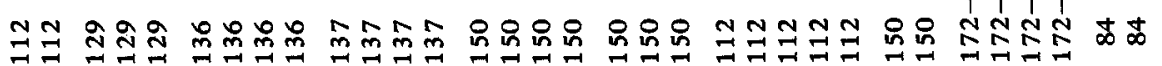

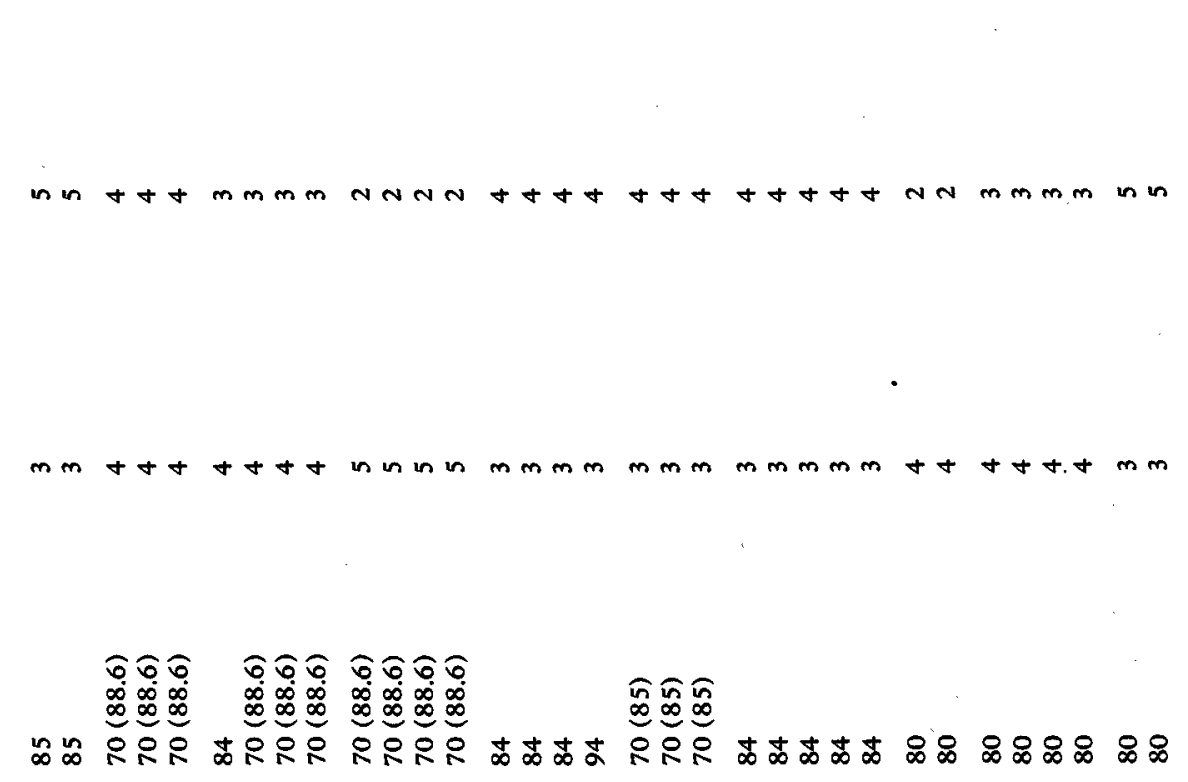

$a$

음

$\sim \stackrel{m}{\sim}$ 


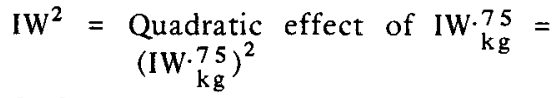

$\beta_{1}, \beta_{2}=$ Partial regression coefficients $\epsilon=$ Random errors

The treatment-trial classification variable $\left(\alpha_{\mathbf{i}}\right)$ served to account for variation in trials due to grains, processing method, sex, length of trial, et cetera. Of interest was the effect that differences in initial weight (IW) on test had on measures of performance. Pen average initial weights ranged from 172 to $342 \mathrm{~kg}$ which corresponds to 47.4 and $79.4 \mathrm{~kg} .75$, respectively.

Importance of the treatment-trial classification variable, initial weight and the quadratic effect of initial weight was verified with the model above for INTAKE, ADG and F/G. The treatment classification was then eliminated from the model resulting in a second model with a trial classification $\left(T_{i}, i=1,2, \ldots, 14\right)$, IW and IW ${ }^{2}$ as follows:

$$
\mathrm{Y}=\beta \mathrm{o}+\mathrm{T}_{\mathrm{i}}+\mathrm{IW} \beta_{1}+\mathrm{IW} \mathrm{W}^{2} \beta_{2}+\epsilon
$$

Where: $Y=$ INTAKE $(\mathrm{kg})$, ADG $(\mathrm{kg})$ or $F / G$ $\beta_{O}=\mathrm{Y}$ intercept

$\mathrm{T}_{\mathrm{i}}=$ Trial classification variable, $\mathrm{i}=1$, $2, \ldots, 14$

IW = Initial weight on test in $\mathrm{kg}_{\mathrm{kg}}^{75}=$ IW. 75

$\mathrm{IW}^{2}=$ Quadratic effect of $\mathrm{IW} \cdot \underset{\mathrm{kg}}{75}=$ $(\mathrm{IW} \cdot \mathrm{kg})^{2}$

$\beta_{1}, \beta_{2}=$ Partial regression coefficients $\epsilon=$ Random errors

Thus, this second model differs from the first one only in that $T_{\mathfrak{i}}$ represents the trial classification variable; whereas, $\alpha_{1}$ represented the trial and treatment classification variable in the first model.

The data were subjected to multiple regression procedures to determine how well laboratory analyses of grain would substitute for the treatment classification variable in predicting performance for INTAKE, ADG and F/G. These are referred to as predicted values. This was accomplished by fitting the data to the second model and using the maximum $\mathrm{R}^{2}$ procedure (Service, 1972) with laboratory analyses as independent variables and INTAKE, ADG and $F / G$ residuals as dependent variables. The maximum $\mathbf{R}^{2}$ procedure looks for the "best" one variable model, the "best" two variable model and so forth. It first finds the one variable model producing the highest $R^{2}$ statistic. It then adds the next variable which would yield the greatest increase in $R^{2}$. Each of the variables in the model is compared to each variable not in the model. The procedure determines if removing the variable in the model and replacing it with the presently excluded variable would result in an increased $\mathbf{R}^{2}$. After all comparisons are made, the switch which produces the greatest increase in $R^{2}$ is made. Comparisons are made again, and the procedure continues until it finds no switch which will increase $R^{2}$. This is considered the "best" two-variable model. A third variable is added, and the process continues.

Residuals (the differences between predicted and observed values) were obtained for the model including $T_{i}, I W$ and $I W^{2}$, and correlations between the residuals and the various laboratory analyses were obtained. Correlations obtained in this manner, therefore, represented correlations between adjusted dependent variables and laboratory analyses of the grains.

\section{RESULTS AND DISCUSSION}

Relationships between Initial Weight and Performance. Multiple regression equations with INTAKE, ADG and F/G as dependent variables and treatment-trial classification $\left(\alpha_{i}\right)$, IW and IW ${ }^{2}$ as independent variables are shown in table 2. These equations are based on all 162 pens of cattle. It should be pointed out that those equations are not designed as prediction equations since slope and intercept coefficients may vary among treatment-trial classifications. Rather, the equations describe the average response observed over all pens of cattle.

The equation for the dependent variable INTAKE suggests that as IW (recall this is on metabolic body weight basis) increases INTAKE increases in an apparent linear fashion. The regression of INTAKE on IW, IW ${ }^{2}$ and $\alpha_{i}$ accounted for $91.38 \%$ of the variation observed in INTAKE in these data. However, the $\mathrm{R}^{2}$ of the simple linear regression model with $\alpha_{i}$ (treatment-trial classification variable) alone was $89.47 \%$, indicating its importance relative to the initial weight components. The effect of IW after adjusting for $\alpha_{i}$ was significant, however $(\mathrm{P}<.0001)$. As observed with INTAKE, ADG (table 2) increased with increasing IW; however, the quadratic effect of initial weight $\left(\mathrm{IW}^{2}\right)$ was significant $(P<.0109)$ after adjustment for $\alpha_{i}$ and IW. This suggests that cattle of 
TABLE 2. MULTIPLE REGRESSION EQUATIONS FOR DEPENDENT VARIABLES, INTAKE, ADG, AND F/G. ADJUSTED FOR TREATMENT-TRIAL CLASSIFICATION AND INITIAL WEIGHT EFFECTS

\begin{tabular}{|c|c|}
\hline Item & Equation \\
\hline Intake & $\begin{array}{l}\mathrm{Y}=4.302+\left(\alpha_{i}\right)^{\mathrm{a}}+.0174\left(\mathrm{IW} \mathrm{kg}_{\mathrm{kg}}^{75}\right)+.0005\left(\mathrm{IW}_{\mathrm{kg}}^{75^{\mathrm{b}}}\right)^{2} \\
\mathrm{Sy}(\mathrm{x})=.4504 \\
\mathrm{R}^{2}=.9138\end{array}$ \\
\hline$A D G$ & $\begin{array}{l}Y=3.1797+\left(\alpha_{i}\right)-.07398\left(\mathrm{IW}_{\mathrm{kg}}^{75}\right)+.0068\left(\mathrm{IW}_{\mathrm{kg}}^{75}\right)^{2} \\
\mathrm{Sy}(\mathrm{x})=.1096 \\
\mathrm{R}^{2}=.8393\end{array}$ \\
\hline$F / G$ & $\begin{array}{l}\mathrm{Y}=-7.7505+\left(\alpha_{\mathrm{i}}\right)+.4371\left(\mathrm{IW}_{\mathrm{kg}}^{75}\right)+.0035\left(\mathrm{IW}_{\mathrm{kg}}^{75}\right)^{2} \\
\mathrm{Sy}(\mathrm{x})=.4388 \\
\mathrm{R}^{2}=.7872\end{array}$ \\
\hline
\end{tabular}

heavier starting weights gained relatively more rapidly, on a metabolic body weight basis, than those of lighter starting weights in these data. This is likely due to compensatory gain effects in cattle which were older and heavier at the start of the trial. For the variable ADG, the regression on $\mathrm{IW}, \mathrm{IW}^{2}$ and $\alpha_{\mathrm{i}}$ accounted for $83.93 \%$ of the observed variation, although $\alpha_{i}$ alone accounted for $82.44 \%$. Similar results have been reported by Luetingh (1963) in terms of increases in intake and gain with cattle fed concentrate diets at different weights and ages.

For the variable $F / G$ (table 2 ), the quadratic effect of initial weight was significant $(\mathrm{P}<.0014)$ after adjustment for $\alpha_{i}$ and IW, suggesting cattle of heavy starting weights tended to be more efficient than those of intermediate weights. The reason for this trend is not readily apparent but may be due to compensatory gain in heavier, older cattle. Moreover, such cattle may have shown a slightly greater dilution of maintenance resulting in improved $\mathrm{F} / \mathrm{G}$, since heavier, older cattle also gained relatively more rapidly. Regression of $\mathrm{F} / \mathrm{G}$ on $\alpha_{\mathrm{i}}$, IW and $\mathrm{IW}^{2}$ accounted for $78.72 \%$ of observed variation in F/G. However, $\alpha_{i}$ alone accounted for a large percentage of the variation (76.18\%). Luetingh (1963) observed a trend for pooorer TDN and gross energetic efficiency as cattle increasing in weight and age were fed 2:1, concentrate: roughage diets. His observations were likely related to altered body compositional changes.

It should be noted that even though the effects of IW were significant in all cases and $\mathrm{IW}^{2}$ in two of the three, the $\alpha_{\mathrm{i}}$ classification variable fitted in a simple linear regression model consistently accounted for a large percentage of the total variation.

Lab Analyses and Feedlot Performance. The ability of the various laboratory analyses to account for variation among residuals in the dependent variables (INTAKE, ADG or F/G), after correction for trial and initial weight effects, is shown in table 3. Since as noted previously, GEL data were available on only 72 pens of cattle, these results are shown with GEL either allowed or not allowed as variable for choice by the maximum $\mathrm{R}^{2}$ procedure. Recall that residuals from the second model $\left(T_{i}, I W\right.$ and $\left.I^{2}\right)$ were the dependent variables for the procedure. Laboratory analyses accounted for more of the variation among residuals in INTAKE $(17.81 \%)$ and $F / G$ (34.96\%) than for ADG (5.16\%). This was true whether or not GEL was included as possible selection. When GEL was included as a possible selection, the maximum variation accounted for was $28.49 \%$ for INTAKE, $28.60 \%$ for $F / G$ and $15.62 \%$ for ADG. Thus, the laboratory analyses considered in this study would have more predictive value for INTAKE and F/G than for ADG; however, the actual percentage of variation among residuals accounted for by the various laboratory analyses was relatively small in all cases. If cattle eat to satisfy energy needs, and thus gain, on high concentrate diets, it is logical that the variation accounted for in ADG in this procedure would be lower than for 
TABLE 3. VARIATION AMONG RESIDUALS FOR DEPENDENT VARIABLES INTAKE, ADG AND F/G ACCOUNTED FOR BY MAXIMUM $\mathbf{R}^{2}$ SELECTED SINGLE OR COMBINATION LABORATORY ANALYSES AFTER CORRECTION FOR TRIAL AND INITIAL WEIGHT EFFECTS $\mathbf{a}, \mathbf{b}$

\begin{tabular}{|c|c|c|}
\hline Variable & Laboratory analyses & $\begin{array}{l}\% \\
\text { Variation } \\
\text { among } \\
\text { residuals } \\
\text { accounted } \\
\text { for }\end{array}$ \\
\hline & \multicolumn{2}{|c|}{ GEL out of model ( 130 pens of cattle) } \\
\hline INTAKE & $\begin{array}{l}\text { IV24* } \\
\text { GP1*, GP6* } \\
\text { GP1*, GP6*, IV24* } \\
\text { GP1 *, GP6*, IV6, IV12* } \\
\text { GP1 *, GP6, IV6, IV12, IV24 }\end{array}$ & $\begin{array}{r}3.79 \\
11.13 \\
16.30 \\
17.72 \\
17.81\end{array}$ \\
\hline ADG & $\begin{array}{l}\text { GP6* } \\
\text { GP1*, GP6* } \\
\text { GP1, GP6*, IV24 } \\
\text { GP1, GP6*, IV12, IV24 } \\
\text { GP1, GP6*, IV6, IV12, IV24 }\end{array}$ & $\begin{array}{l}2.80 \\
4.84 \\
5.06 \\
5.15 \\
5.16\end{array}$ \\
\hline \multirow[t]{2}{*}{$F / G$} & $\begin{array}{l}\text { GP6* } \\
\text { GP1*, GP6* } \\
\text { GP1*, GP6*, IV12* } \\
\text { GP1*, GP6*, IV6, IV12* } \\
\text { GP1*, GP6*, IV6, IV12, IV24 }\end{array}$ & $\begin{array}{l}10.71 \\
30.77 \\
34.12 \\
34.96 \\
34.96\end{array}$ \\
\hline & \multicolumn{2}{|c|}{ GEL in model ( 72 pens of cattle) } \\
\hline INTAKE & $\begin{array}{l}\text { GEL* } \\
\text { IV24*, GEL* } \\
\text { GP1*, GP6*, IV24* } \\
\text { GP1*, GP6*, IV6*, IV24* } \\
\text { GP1*, GP6*, IV6*, IV24*, GEL } \\
\text { GP1*, GP6*, IV6, IV12, IV24, GEL }\end{array}$ & $\begin{array}{r}5.03 \\
9.04 \\
22.15 \\
28.15 \\
28.49 \\
28.49\end{array}$ \\
\hline ADG & $\begin{array}{l}\text { GP6* } \\
\text { GP1*, IV24 } \\
\text { GP1 }{ }^{*}, \text { IV12, IV24* } \\
\text { GP1 }{ }^{*} \text { IV6, IV12, IV24* } \\
\text { GP1, GP6, IV12, IV24*, GEL } \\
\text { GP1, GP6, IV6, IV12, IV 24*, GEL }\end{array}$ & $\begin{array}{r}5.13 \\
12.21 \\
14.29 \\
14.71 \\
15.47 \\
15.62\end{array}$ \\
\hline F/G & $\begin{array}{l}\text { GP6* } \\
\text { GP1*, GP6* } \\
\text { GP1*, GP6*, GEL } \\
\text { GP1*, GP6*, IV6, GEL* } \\
\text { GP1*, GP6*, IV6, IV12, GEL } \\
\text { GP1*, GP6*, IV6, IV12, IV24, GEL }\end{array}$ & $\begin{array}{l}16.25 \\
22.62 \\
24.23 \\
26.22 \\
28.53 \\
28.60\end{array}$ \\
\hline
\end{tabular}

*Significant regression $\mathrm{F}(\mathrm{P}<.10)$.

${ }^{a}$ Model from which residuals wete derived. $Y=\beta_{0}+\Upsilon_{i}+I W \beta_{1}+I W^{2} \beta_{2}+\epsilon$ accounted for 80.51, 74.73 and $52.64 \%$ of variation in INTAKE, ADG and F/G, respectively, for all 162 pens of cattle.

${ }^{b}$ Simple linear regression model with $Y=\beta o+\Upsilon_{i}+\epsilon$ accounted for $78.45,73.40$ and $49.46 \%$ of variation in INTAKE, ADG and F/G, respectively, for all 162 pens of cattle.

INTAKE and F/G. Since dietary energy intake is not limited by bulk fill in high-concentrate diets, ADG would be largely a function of genetic potential. As laboratory analyses tend to measure factors related to energy values, they might not be expected to account for as 


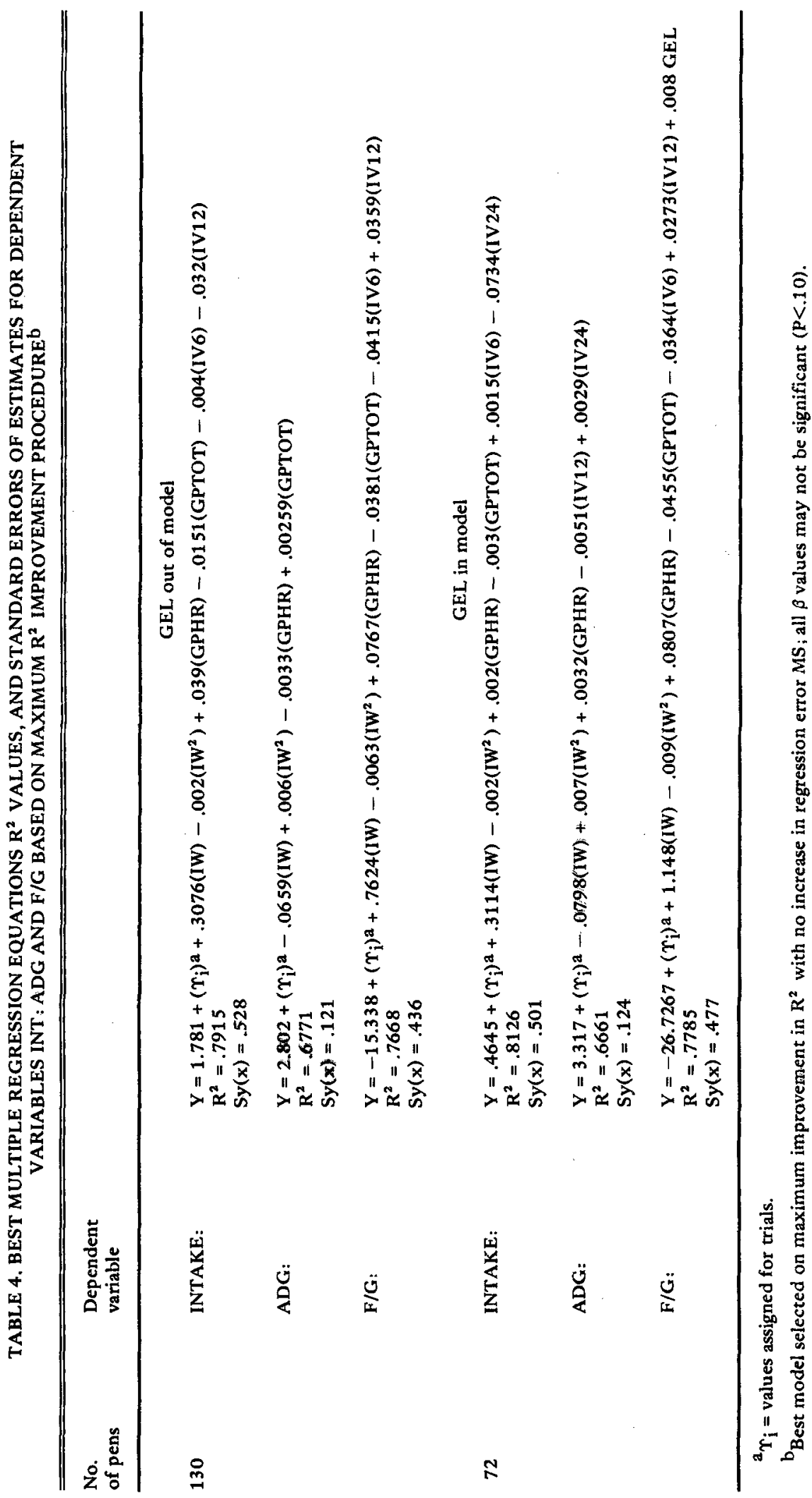


much variation in ADG as in INTAKE and F/G.

Multiple regression equations based on the "best" combination of laboratory analyses are shown in table 4. The best combination was one that resulted in maximum improvement in $\mathbf{R}^{2}$ with no increase in the regression error mean square. These combinations were fit in to a model which included trial and initial weight effects $\left(Y=\beta_{0}+T_{i}+I W \beta_{1}+I W^{2} \beta_{2}+L A_{i} \beta_{3}\right.$ $\ldots . \mathrm{LA}_{\mathrm{n}} \beta_{\mathrm{n}}+\epsilon$, where $\mathrm{LA}_{\mathrm{i}}=$ ith lab analysis). As noted previously, the greatest $R^{2}$ values were obtained with the dependent variables INTAKE and $F / G$. Regression equations and $R^{2}$ values were similar whether or not GEL was considered. Note also that $\mathrm{R}^{2}$ values resulting from these models are lower than those shown in table 2 when a treatment classification was included in the model $(79.15 \%$ vs $91.38 \%$ for INTAKE in table $4 v$ s table 2). It is noteworthy, however, that the $\mathrm{R}^{2}$ of $76.68 \%$ for $\mathrm{F} / \mathrm{G}$ in table 3 (GEL out of model) is similar to the $\mathrm{R}^{2}$ in table 2 of $78.72 \%$, indicating that these analyses have predictive value for $F / G$.

It is important to consider that, based on information presented thus far, no single laboratory analysis would be a good predictor of animal performance. It would appear that combinations of laboratory analyses would be the most promising means of developing prediction equations. To further investigate the association between performance parameters (INTAKE, ADG, F/G) and various laboratory grain analyses, correlation analyses were per- formed on the data (table 5). Correlations of INTAKE with the various laboratory analyses are small (e.g., IV24 $=-.36, \mathrm{GEL}=-.22$ ) and do not indicate a strong association, although many are significant. The fact that all the correlation coefficients are negative, however, is in agreement with the general belief that as gelatinization, starch availability and digestibility increase, intake should decrease as energy availability increases.

Similar results were again obtained with F/G, with all correlation coefficients being rather small and negative $(-.22$ and -.32 for IV24 and GEL, respectively). Nevertheless, correlations were highly significant $(P<.01)$ for GP6, IV24 and GEL. The same rationale for negative correlations with INTAKE would apply to F/G.

Correlation coefficients between ADG and the laboratory analyses were all small and non-significant, thus, reaffirming the low $R^{2}$ values previously discussed in tables 3 and 4 . In general, correlations between all dependent variables and laboratory analyses are not of the magnitude necessary for development of accurate, reliable prediction equations using any single analysis. These results are in contrast to those of Albin et al. (1966) who report $\mathrm{r}$ values of .88 and .99 between IVDMD and feedlot gain and efficiency, respectively.

Correlations among the various laboratory analyses are shown in table 6 . These correlations, uncorrected for trial differences, reveal

TABLE 5. CORRELATIONS BETWEEN INT, ADG, AND F/G CORRECTED FOR TRIAL AND INITIAL WEIGHT EFFECTS AND VARIOUS LABORATORY ANALYSES

\begin{tabular}{|c|c|c|c|c|c|c|}
\hline \multirow[b]{2}{*}{ Variable } & \multicolumn{6}{|c|}{ Laboratory analyses } \\
\hline & GP1 & GP6 & IV6 & IV12 & IV 24 & GEL \\
\hline INTAKE & $\begin{array}{r}-.0152^{a} \\
130^{.8583^{b}}\end{array}$ & $\begin{array}{r}-.1633 \\
130.0600\end{array}$ & $\begin{array}{r}-.0879 \\
130^{.6796}\end{array}$ & $130^{. .1501}$ & $162^{. .3609}$ & $\begin{array}{r}-.2242 \\
72.0552\end{array}$ \\
\hline ADG & $130^{.0648}$ & $130^{.0538}$ & $130^{.0278} .7523$ & $\begin{array}{r}-.0178 \\
130^{.8351}\end{array}$ & $162^{. .1418}$ & $72^{.0952}$ \\
\hline $\mathrm{F} / \mathrm{G}$ & $130^{. .0911}$ & $130^{-.3272}$ & 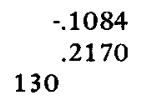 & $\begin{array}{r}-.1157 \\
130\end{array}$ & $162^{. .2175}$ & $\begin{array}{r}-.3177 \\
72.0066\end{array}$ \\
\hline
\end{tabular}

\footnotetext{
${ }^{a}$ Correlation coefficients.

$b_{\text {Significance level. }}$

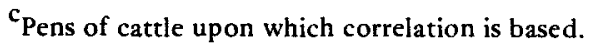


TABLE 6. CORRELATIONS AMONG VARIOUS LABORATORY ANALYSES

\begin{tabular}{|c|c|c|c|c|c|}
\hline \multirow[b]{2}{*}{ Variable } & \multicolumn{5}{|c|}{ Laboratory analyses } \\
\hline & GP1 & IV6 & IV12 & IV24 & GEL \\
\hline GP1 & $130^{.0001^{b}}$ & $130^{.0001}$ & $130^{.0001}$ & $130^{.0001}$ & $72^{.0462}$ \\
\hline GP6 & $\ldots$ & $130^{.0001}$ & $130^{.0003}$ & $130^{.0005}$ & $72^{.06684}$ \\
\hline IV6 & $\ldots$ & $\cdots$ & $130^{.0001}$ & $130^{.0001}$ & $\begin{array}{r}-.2349 \\
72.0443\end{array}$ \\
\hline IV12 & $\cdots$ & $\cdots$ & $\cdots$ & $130^{.9029}$ & $72^{-.2094}$ \\
\hline IV24 & $\cdots$ & $\cdots$ & $\cdots$ & $\cdots$ & $\begin{array}{r}-.2119 \\
72^{.0704}\end{array}$ \\
\hline
\end{tabular}

\footnotetext{
${ }^{\text {a }}$ Correlation coefficients.

${ }^{\mathrm{b}}$ Significance level.

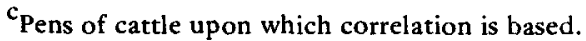

strong and generally obvious associations among several of the analyses. The significant correlation of .668 between GP6 and GEL supports the idea that gas production values provide information similar to gelatinization values in regards to the extent of starch alteration. The high, significant correlations between the three IVDMD measures (.9029 for IV12 and IV24) are expected as they are consecutive measures on the same sample.

The correlations between GP6 and any of the IVDMD measures were not as high as that reported by Trei et al. (1970). However, the gas production method used in our studies was a $\beta$ amyloglucosidase enzyme and yeast utilization procedure; whereas, Trei et al. (1970) used rumen microorganisms in their gas production system.

In conclusion, it appears that no single laboratory analysis of grain will predict performance of animals fed that grain with a high degree of accuracy. Combinations of the lab analyses may have been predictive value for certain performance measures (e.g., F/G); however, it would seem that these analyses better serve the purpose of describing the effects of processing and extent of starch alteration in grains.

\section{LITERATURE CITED}

Aimone, J. C. 1975. Feedlot, in vitro and metabolism studies with processed wheat and barley. M. S. Thesis, Oklahoma State University.

Aimone, J. C. and D. G. Wagner. 1977a. Micronized wheat. I. Influence on feedlot performance, digestibility, VFA and lactate levels in cattle. J. Anim. Sci. 44: 1088.

Aimone, J. C. and D. G. Wagner. 1977b. Micronized wheat. II. Influence on in vitro digestibility, in vitro gas production and gelatinization. J. Anim. Sci. 44: 1096.

Albin, R. C., A. Simnacher and R. M. Durham. 1966. In vitro digestion of all-concentrate ration. Rep. on Texas Technological College Research 55.

Christiansen, R. R. and D. G. Wagner. 1974a. Reconstituted wheat. I. Influence on feedlot performance of cattle. J. Anim. Sci. 38:456.

Christiansen, R. R. and D. G. Wagner. 1974b. Reconstituted wheat. II. Influence of physical form on in vitro digestibility. J. Anim. Sci. 38:463.

Croka, D. C. and D. G. Wagner. 1975a. Micronized sorghum grain. I. Influence on feedlot performance of cattle. J. Anim. Sci. 40:924.

Croka, D. C. and D. G. Wagner. 1975b. Micronized sorghum grain. II. Influence of in vitro digestibility, in vitro gas production and gelatinization. J, Anim. Sci. 40:931.

Croka, D. C. and D. G. Wagner. 1975c. Micronized sorghum grain. III. Energetic efficiency for feedlot cattle. J. Anim. Sci. 40:936.

Klett, R. H. and A. T. Ralson. 1967. A comparison of in vitro and in vivo digestion techniques. J. Anim. 
Sci. 26:922. (Abstr.).

Kumeno, F., B. A. Dehority and R. R. Johnson. 1967. Development of an in vitro fermentation technique for estimating the nutritive value of high energy mixed rations for ruminants. J. Anim. Sci. 26:867.

Leutingh, H. C. 1963 . The efficiency of beef production in terms of carcass weight as influenced by the ration concentration and age of steers. J. Agr. Sci. $61: 127$.

Martin, T. 1973. Feedlot and in vitro studies with processed sorghum and wheat. M. S. Thesis, Okla- homa State University.

Schneider, William. 1971. In vivo and in vitro evaluation of high moisture milo and milo-wheat combinations for fattening beef cattle. M. S. Thesis, Oklahoma State University.

Service, Jolayne. 1972. A user's guide to the statistical analysis system. North Carolina State University. P. 127.

Trei, J., W. H. Hale and Brent Theurer. 1970. Effect of grain processing on in vitro gas production. J. Anim. Sci. 30:825. 